\title{
A Comparative Study on the Development Paths of OFDI in China and Japan
}

\author{
Wei Liu $^{1}$ \\ ${ }^{1}$ School of Economics, Guizhou University of Finance and Economics, Guiyang City, Guizhou \\ Province, China
}

Keywords: Go Out; Ofdi; The Belt And Road Initiative.

\begin{abstract}
With China's continuous opening up to the outside world and the pace of "going out", China's OFDI growth is accelerating, especially development strategy of "the Belt and Road Initiative" issued in recent years, which highlights that China has attached great importance to the development of OFDI. In this paper, through the comparisons of the development path of OFDI in China and Japan, we can have a preliminary understanding of the development of domestic OFDI, grasp the rationality of the development of OFDI in China and put forward the relevant policy suggestions.
\end{abstract}

\section{Introduction}

Since the reform and opening up, China's economic development is very rapid, especially after China's accession to the WTO in 2001. Since then, China's comprehensive national strength has been rising and its international economic status and influence is also different from the past. In this case, the domestic economy rapidly develops. China has "cultivated" a large number of international competitive enterprises. As early as in 2000, China has attached the importance of OFDI and encouraged Chinese enterprises to "go to the outside world". In November, 2014, the APEC was held in Beijing, which achieved many encouraging results, including the Asian Infrastructure Investment Bank and the Foundation for the Silk Road. To certain extent, China's capital output has turned to a new chapter. In this case, the domestic enterprises should seize this opportunity. [1]

With China's reform and opening up, Japan also has impressive economic growth after World War II. Especially after 1969, Japan has gradually got rid of the influences of the balance of payment deficit. Through the industrial transfer of the developed countries in Europe and the United States, Japan has made great efforts to develop its own economy and optimized its industrial structure. Compared with the neighboring Asian countries, Japan has gradually accumulated the huge technological advantage and the capital advantage. As an island country, Japan's resources are scare. It regards the OFDI as a dynamic and sustained economic power, In the 1980s, the Japanese economy has reached its peak.

Although the development path of China's economy is quite different from that of Japan in the 1980s, they still have some similarities, such as the shortage of resources per capita, the gradual loss of labor, the economic pressure caused by the currency appreciation and so on. China now faces many problems which have occurred in Japan before. Therefore, the domestic enterprises can learn from Japan in OFDI.

\section{The Present Situation of China and Japan's OFDI}

Since the reform and opening up, China's OFDI has gradually developed and its scale has become larger, especially after China's accession to the WTO. In December 11, 2001, China formally joined the World Trade Organization (WTO), becoming its 143rd member. At that time, the main purpose of China's accession to the WTO is to attract the foreign capital to support the overall construction of China. After the first year of China's accession to the WTO, China's OFDI was 2.7 billion dollars in 2002 while the amount of foreign capital used was 52.7 billion dollars. The OFDI is only a fraction of the amount of foreign capital used. In 2014, China's OFDI was more than 120 billion dollars. From 2002 to 2014, China's foreign investment soared by 45 times. According to the Ministry of 
Commerce's prediction, China's foreign investment in the next 10 years will increase by an annual rate of more than 10\%. China's foreign investment is likely to exceed 200 billion dollars in 2020 . The EIU issued a report on Chinese Overseas Investment Index in the media conference held in November of last year, which predicts that in 2017, China will become the largest net investment country in the world and its scale of overseas investment will be ranked the first in the world. In recent years, Japan has stepped up its efforts to invest abroad because of the continuing decline in Japan's birth rate, the acceleration of the aging population and the shrinking domestic demands. The statistics issued by Japan's Ministry of Finance shows that Japan's OFDI amounted to 135.094 billion dollars in 2013 with an increase of $10.4 \%$ over the previous year. This is the highest record in history and keeps the growth rate over $10 \%$ in the third year. In 2013, Japan's OFDI mainly concentrated in the United States, East Asia and Europe and other countries and regions, accounting for more than $90 \%$ of the total OFDI. In terms of the nations, the United States is Japan's largest investment target last year. The investment in the United States was 43.7 billion dollars, accounting for $32.4 \%$ of the total amount of Japan's foreign investment. However, for China, the rapid growth of Chinese economy caused the rising wages, the rising production costs. Thus, Japanese investors' investment enthusiasm was affected. Furthermore, some large projects have reduced in the last year and the Sino-Japanese relation was deteriorated. The Japanese enterprises prefer to wait and see, leading to the decline in the amount of annual investment in China. In the last year, Japan's investment in China was 9.1 billion dollars, decreased 32.5\% over the previous year. However, JETRO's survey of the enterprises' trends showed that although the Japan's OFDI in China has a substantial decline, 54.6\% of the enterprises will continue to expand or add their investment and business in China due to China's huge market and strong demands.

\section{Comparisons of the Investors in China and Japan}

China's OFDI investors. China's investors of OFDI are diverse. In terms of the industry, the property right and the administrative subordination and other aspects, China's investors are still relatively complex. The diversification of the investors reflects that after China's opening up, China's various economic composition coexist and it positively influences the foreign economic activities. From a professional point of view, the central and local enterprises and the state-owned multinational enterprises which are specialized in foreign trade have large-scale production. A variety of the professional foreign trade enterprises have a long history of foreign trade and rich experience in trade. They have huge wealth and many workers who are familiar with foreign trade. However, in certain period of the future, the professional foreign trade enterprises' capital strength is difficult to meet the development of the large enterprises and its advantages will gradually be replaced. The central and local governments and the large state-owned multinational enterprises, especially the large enterprises with the combination of industry, technology and trade have a unique potential for foreign investment. Therefore, the production of the multinational enterprises will continue to become the main force of China's foreign investment. However, the proportion of China's small and medium-sized multinational enterprises is too high and they will not become large-scaled. Even some so-called large multinational enterprises are actually small ones when compared to those of the developed countries. Therefore, Chinese should also form a transnational corporation, similar to General Trading Company in Japan which plays an important role in the international market and reflects the small and medium-sized enterprises' competition.

Japan's OFDI investors. Compared with other developed countries, Japan started late. As a newly developed country, it should compete with other developed countries. It should encourage the multinational enterprises to play its unique role, namely regarding the multinational enterprises as the investors of OFDI. Facing the urgent demand of increasing competition, the industrial, commercial and financial enterprises in Japan have mutually integrated and formed an new type of overseas investment subject with relatively high-level and particularity, that is, General Trading Company. Currently, the company has the function of trade, finance, information, organization, coordination and development. With some large manufacturing groups and transnational banks, which consists the main part of the investors in the developed countries. At the same time, Japan's large companies also 
cooperate with small and medium-sized to conduct OFDI. For the large enterprises, Japan provides them technology, information, capital, contributing to the investment of the small and medium-sized enterprises in the developing countries, so that it forms an enterprise group of production and sales with interdependent, complementary.

Comparisons of the investors of China and Japan. In terms of function and structure, the OFDI investors of China and Japan are roughly the same, that is, large enterprises are the main investment subject of OFDI which is a breakthrough in foreign investment. In terms of small and medium enterprises, the proportion of these enterprises in the foreign investment is little. As time passed by, the small and medium-sized enterprises of the two countries will play a more and more important role in foreign investment. And their status will be higher and higher. In terms of the enterprise division, the two countries are significantly different. For China's enterprises, in the division of the central and local enterprises, it not simply refers to the difference between state-owned and private enterprises. They are classified according to the local division, causing the problem that the local place still has a large number of state-owned enterprises. [2] Therefore, it can be inferred that the number of the state-owned enterprises in our country is very large while the proportion of the private enterprises is very small. But for Japan, the enterprise constitute is reasonable with clear division. Both the large and small enterprises have their own advantages. The small and medium-sized enterprises are more flexible. Their technical advantages are obvious while the large enterprises hold the lifeline of the national economy.

\section{Comparison of the OFDI Industries in China and Japan}

China's OFDI industries. In terms of the OFDI industries, there is a wide range and the trend is more obvious. In 2012, the investment more than billions of dollars mainly concentrated in the seven industries, accounting for 92.4\% of China's total OFDI. In 2013, the investment is further concentrated in five industries, that is, the leasing and business services, financial services, mining, wholesale and retail, manufacturing, with the total investment of 548 billion dollars, accounting for $83 \%$ of China's total OFDI. From the distribution of these industries, China's OFDI industries are mostly in the service industry with producibility while the industries such as education and health care are quite limited. From the development trend, according to the net foreign direct investment, the proportion of the mining industry, the wholesale and retail industry, the manufacturing industry accounting for total net foreign direct investment is improving while the proportion of the leasing and business services and the finance is decreased. [3]

Japan's OFDI industries. From the transformation of the export structure, it can be clearly seen that due to the adjustment of the industrial structure, the proportion of agriculture in export has been declined in five years, which gradually causes to the decrease of the food and textiles relevant to agriculture. This is in line with the actual situation in Japan, which will make the best use of its labor and land resources. According to the previous analysis, Japan issued some support policies in the 1970 s and the 1980s to promote the export structure in favor of chemical products, mechanical equipment and other products of secondary industry in the chemical industry, especially in the automotive manufacturing industry, computer and other high-tech industry. At that time, these policies promoted the smooth trading and took its advantages of technic and cost, which contributed to Japan's rapid development. On the other hand, the volume of trade promotion has also stimulated its industrial development and prosperity. [4] A large number of the export industrial products, such as machinery and equipment, have also speed up Japan's mechanization and industrialization, promote the adjustment of the industrial structure in Japan and make the industrial structure more reasonable. In the past ten years, Japan's economy downturn lead to its worse trade. The industrial structure is gradually changing from the finance industry and the service industry, representing the tertiary industry. The traditional pillar industries, such as the automotive industry, electronics industry, show their weakness year by year.

Comparisons of the OFDI industries of China and Japan. In terms of the industries of the foreign investment, there is a huge difference between the two paths of China and Japan, which is mainly determined by the national conditions of the two countries and real economic development. 
China's industrial distribution of OFDI mainly focus on the service industry with producibility, which has lasted for a long time. [5] This is mainly caused by the fact that China's status of superpower in manufacturing industry has not been changed for a long time and the industry is facing the huge adjustment. Therefore, we have to be the manufacturing powerhouse. With the present status, China's OFDI cannot escape of the service industry with producibility. However, Japan changes its strategies according to its changing economy, as well as its OFDI It focuses on the resources industry at the beginning and gradually transits to the manufacturing industry. With the signing of the Plaza Agreement, Japan's OFDI gradually shifts to the tertiary industry. It is gradually developing. Thus, on the whole, China's industrial distribution of OFDI is superior to that of Japan. There is still huge gap between China's manufacturing industry and Japan's, which has not made the best use of science and technology in the industry. [6]

\section{Policy Suggestions}

From the above comparisons between China and Japan, we can found that Chinese investors are mainly large state-owned enterprises while few private enterprises participate in it. In China, the investors prefer to the service industry with producibility, which is quite different from those in japan. According to the above conclusions, we should be aware of some problems existing in Chinese OFDI, as well as the gap between Chinese and Japanese OFDI. Combined with China's reality and the successful cases of the developed countries, such as Japan, we put forward the reasonable suggestions.

First, we should distinguish the state-owned enterprises and the local enterprises. Namely, we should vigorously support our private enterprises, make them energetic and enough their enthusiasm to participate in OFDI. In recent several years, the private enterprises have rapidly developed. If we only rely on the state-owned enterprises' OFDI, the development of China's OFDI is obviously inadequate. Only the state-owned enterprises and the private enterprises are driven to develop, the long-term development of China's OFDI will be achieved.

Second, China's industrial transformation and upgrading should be carried out. The industrial distribution of China's OFDI is unreasonable, which excessively relies on the service industry with producibility and does not take the advantages of other industries. This is determined by China's manufacturing power. Therefore, we should make the corresponding adjustment of China's industry. We should rely on science and technology and play their role in the industry. We should gradually reform the domestic manufacturing industry, integrate the industrial chain, increase the added value, increase its value and finally improve China's unreasonable industrial distribution of OFDI.

Third, we must rely on the government's positive guidance. In OFDI, only relying on the enterprises' own strength is not enough. The government should play its role, strengthening its guidance and actively guiding the enterprises to release overseas news timely. At the same time, the government can help the enterprises solve a series of problems, such as the financing, or give the enterprises a series of preferential tax policies. For the enterprises "going to the outside world", the government can reduce the relevant tax.

\section{References}

[1] Xin Li. Research on the Obstacles and Countermeasures of Chinese Enterprises' Foreign Direct Investment [D]. Changchun: Jilin University, 2014.

[2] Jian-guang Tang. Comparison and Enlightenment of Chinese and Japanese Foreign Direct Investment [J]. Contemporary Finance \& Economics, 2007 (11).

[3] Wen-jv Wang \& San-xing Wang. A Comparative Analysis of the Overseas Direct Investment of Japan and That of China [J]. Finance and Trade Research, 2002 (1).

[4] Qiang Wu. A Comparative Study on the Foreign Direct Investment Between China and Japan [D]. Changchun: Jilin University, 2012. 
[5] Feng-bin Zhao. Japan's Foreign Economic Relations [M]. Beijing: University of International Business and Economics Press, 1990.

[6] Qiang Hu. Comparison and Enlightenment of Foreign Direct Investment Between China and Japan [J]. Northern Economy and Trade, 2015. 